\title{
Negative pressure wound therapy versus healing by secondary intention in pressure ulcers
}

\author{
Roberto Cirocchi, Georgi Popivanov, Ventsislav M Mutafchiyski, Andrea Boccolini, Justus Randolph, Massimo \\ Lancia, Luigi Carlini, Tomasz Banasiewicz
}

\section{REVIEW}

\begin{abstract}
Pressure ulcers are a highly prevalent source of morbidity with an equally high incidence of up to $38.0 \%$ amongst different categories of healthcare institutions. Therefore, the management and therapeutic approach toward these often hospital- or facility-acquired problems remain critical aspects of long-term care. Negative pressure wound therapy (NPWT) has proven effective in addressing the barriers to pressure ulcer healing including increasing blood flow to previously ischemic wound areas by generating subatmospheric pressure which vacuums in circulation. The objective of this study was to compare negative pressure wound therapy (NPWT) versus surgical wounds healing by secondary intention (SWHSI). A systematic literature search was conducted using the PubMed and Scopus search engine up until the 20 Th January 2017 including the terms: "negative pressure wound therapy" and "pressure ulcers". In this systematic review, six randomized controlled trials were included. NPWT is deemed appropriate and effective method and widely used by clinicians to promote the healing of wounds and ulcers of different etiology. The heterogeneity found in individual trials regarding the inclusion criteria, therapeutic procedures, the criteria and methods of outcome evaluation, however, did not allow for a data evaluation with statistically valid conclusions. It is reasonable to assume that a subset of patients with pressure ulcers can be effectively treated with NPWT, with optimal results and good cost-benefit ratio, also with respect to the quality of life.
\end{abstract}

Keywords-NPWT, VAC, Negative pressure wound therapy

\section{INTRODUCTION}

$\mathbf{P}$ RESSURE ulcers are a significant source of morbidity with an equally high incidence of up to $38.0 \%$ amongst different categories of healthcare institutions 12 In particular this condition affects people aged over 65 years with a prevalence ranging from $0.3 \%$ to $46 \%$ and an incidence ranging from $0.8 \%$ to $34 \%\left[\frac{[3}{3}\right.$ Therefore, the management and therapeutic approach toward these often hospital- or facilityacquired problems remain critical aspects of long-term care. ${ }^{4}$ Often, complexities exist structurally within these wounds

Manuscript received 22.09.2017; revised 18.10.2017. This work did not receive any financial support. Authors declare no conflict of interest.

Author affiliations: Department of General and Oncologic Surgery, University of Perugia, Terni, Italy, (RC, AB) ; Military Medical Academy-Sofia, Clinic of Endoscopic, Endocrine surgery and Coloproctology, (GP, VMM) ; Tift College of Education, Mercer University Atlanta, (JR) ; Section of Legal Medicine, University of Perugia, Terni, Italy, (LM, LC) ; Department of General, Endocrine Surgery and Gastrointestinal Oncology,Poznan University of Medical Sciences, Poland, (TB)

*Correspondence to: Roberto Cirocchi: cirocchiroberto@yahoo.it including undermining, tunneling, and sinus tract formation along with exudate and necrotic tissue.$^{5}$ These serve as barriers to healing as they may host resident and occult sources of foreign bodies as well as unreachable nonviable material, both of which may promote ischemia, inflammatory responses, and an increased susceptibility to pathogenic invasion. ${ }^{[6] 10}$ Pressure ulcers and their complications, such as infection and sepsis, especially when hospital-acquired, can raise medico-legal issues. Therefore, an accurate planning of the best therapeutic options for the patient is essential. Negative pressure wound therapy (NPWT) has proven effective in addressing the barriers to pressure ulcer healing including increasing blood flow to previously ischemic wound areas by generating subatmospheric pressure ${ }^{6}$ By suctioning the pro-inflammatory cytokines and enzymes are furthermore decreased, ${ }^{7} 8$ while favorable healing factors such as the infiltration of vascular endothelial growth factor (VEGF) and chemotaxis of fibroblasts increase angiogenesis. $9^{[10}$ Due to the mechanical washout of the wound bed, the pathogenic load is decreased thus indirectly lowering the toxic burden on the pressure wound ${ }^{6}$

\section{Methods}

\section{A. Objectives}

The objective of this study was to compare negative pressure wound therapy (NPWT) versus surgical wounds healing by secondary intention (SWHSI).

\section{B. Types of studies}

Randomized controlled trials (RCTs) were identified through a systematic review of published literature (full article, thesis, or abstract).

\section{Types of participants}

Patients presenting with pressure ulcers in any location.

\section{Types of interventions}

The types of interventions were NPWT in experimental group versus SWHSI in control group (surgical debridement, enzyme or chemical necrosectomy) Types of outcome measures The primary outcomes of interest were summarized 
in efficacy (healed of ulcer, reduction of ulcer volume, local improvement in ulcer characteristics), the secondary outcomes in the socio-economic advantages (consumption of health resources).

\section{E. Studies selection}

A systematic literature search in accordance with the Preferred Reporting Items for Systematic Reviews and Metaanalyses (PRISMA) standards, 11 was conducted using the PubMed and Scopus search engine up until the $20 \mathrm{Th}$ January 2017 including the terms: "negative pressure wound therapy" and "pressure ulcers". No language, publication date, restrictions were imposed. All titles and abstracts of the considered studies were analysed to select only the studies that reported the PICO ( $\mathrm{P}=$ Patient, Population or Problem; $\mathrm{I}=$ Intervention; $\mathrm{C}=$ Comparison; $\mathrm{O}=$ Outcome $) ! 12$ When multiple articles were published from a single study group and overlapping study periods were reported, only the most recent article was considered so as to avoid duplication of data. The Pubmed function "related articles" was used to enlarge each search, and the reference list of all potentially eligible studies was analysed. To minimize retrieval bias, a manual search method including the Science Citation Index Expanded, Scopus and Google Scholar databases was performed. After this initial process, the full-text papers were independently screened by 2 authors for eligibility. The final decision on eligibility was reached by consensus between the 2 screening authors. Data were extracted by 2 authors based on an intention-to-treat principle. Any disagreement was resolved through discussion with a reassessment of the data and/or by involving a third author. The methodological quality assessment of the included studies was evaluated with the instructions and the items given in the Cochrane Handbook for Systematic Reviews of Interventions (sequence generation and allocation concealment for selection bias, blinding of participants or personnel for performance bias, blinding of outcome assessors for detection bias, incomplete outcome data for attrition bias and selective reporting bias, ${ }^{\sqrt{13}} \mathrm{~A}$ protocol for this meta-analysis has been registered on PROSPERO database (ID: CRD42017059678).

\section{RESULTS}

The PRISMA flow diagram for systematic reviews is presented in (Fig. 11). We identified 76 publications using the literature search strategy described above. After excluding 63 records following the review of the titles and abstracts, 13 abstracts eligible for full-text evaluation remained. After full-text assessment, we excluded $7 \operatorname{studied}^{17-23}$ (Tab. If) and identified 6 publications that fulfilled the inclusion criteria which reported data about pressure ulcers (Tab. II).24 29 Quality assessment of the included studies. Since all the included studies are RCTs the quality assessment was based on the risk of bias. Overall risk of bias of the included studies was low as reported in table 3.(Tab. III) In the pressure ulcers analysis, the stage of ulcers was reported in all trials and it was the same (III and IV stage). In three studies the authors described the etiology of immobilization and reported a traumatic paraplegia. The location of ulcer was reported in five studies and it was exclusively sacral in the paper of Dwivedi24 and Wild,27 differently Ashby ${ }^{25}$ and Ford 29 reported a mix of locations: sacral, ischial, lateral malleolar and trochanter region. Overall, 141 patients were enrolled: 62 underwent NPWT and 79 other conventional treatments. All the included trials reported different types of outcomes, so the reported outcomes were not comparable. The analyzed outcomes are extremely numerous and are categorized in some different groups: ulcer healing, reduction of ulcer volume, local improvement in ulcer characteristics and consumption of health resources. Only two trials evaluated ulcer healing: Ashby ${ }^{25}$ and de Laat ${ }^{26}$ In the first study only one pressure ulcer $(16.6 \%)$ which underwent NPWT (79 days) healed; in the other study the authors performed a subgroup analysis of patients with pressure ulcers, but they did not describe the results and reported only the conclusion ("statistically significantly faster wound healing in the topical negative pressure group") 20 (Tab. IV).

Three trials described the reduction in ulcer volume, but the outcome descriptions were very inconsistent [24,28,29]. Dwivedi reported the length and width of ulcer, ${ }^{24}$ differently Wanner reported the mean (SD) time to reach $50 \%$ of the initial volume $e^{28}$ and Ford reported the mean percent reduction in ulcer volume. ${ }^{29}$ In the first study the length and width of an ulcer decreased significantly $(\mathrm{p}<0.01)$ in NPWT group compared to standard care group at week 9.24 In the other two studies the authors did not report a significant difference between the two groups, respectively in Wanner 27 days in NPWT group and 28 in the traditional treatment and $51.8 \%$ with NPWT in Ford and $42.1 \%$ with traditional treatment 28 (Tab. IV). The authors' choice of the characteristics for the local evaluation of ulcer improvement was very heterogeneous. These characteristics were macroscopically evaluated through a biopsy with a histologically examination. In the macroscopic examination, the presence of the granulation tissue was the most important favorable prognostic sign. The evaluation of this tissue was performed in different modalities: newly-formed granulation tissue and wound contracture (measured the volume instead of the area of the usually undermined wounds) as reported from Wanner [28], the absolute and relative proportion of wound surface granulation tissue as reported from Wild 27 or the conversion of slough into red granulation tissue as reported from Dwivedi. ${ }^{24}$ Conversely the presence of exudates, fibrin or necrosis were poor prognostic signs: absolute and relative proportion of fibrin tissue at the wound base or absolute and relative proportion of necrosis. Only few significantly better results were reported in patients who underwent NPWT (lower exudates in NPWT group at weeks 4 and 9 and higher conversion of slough into red granulation tissue, increase in surface granulation), differently the other evaluation did not report report any advantage in macroscopic (newlyformed granulation tissue and wound contracture, absolute and relative proportion of fibrin tissue at the wound base and of necrosis) or biopsy evaluation (mean number of PMNs and lymphocytes per high-power field and mean number of capillaries per high-power field). (Tab. IVP The analysis of 


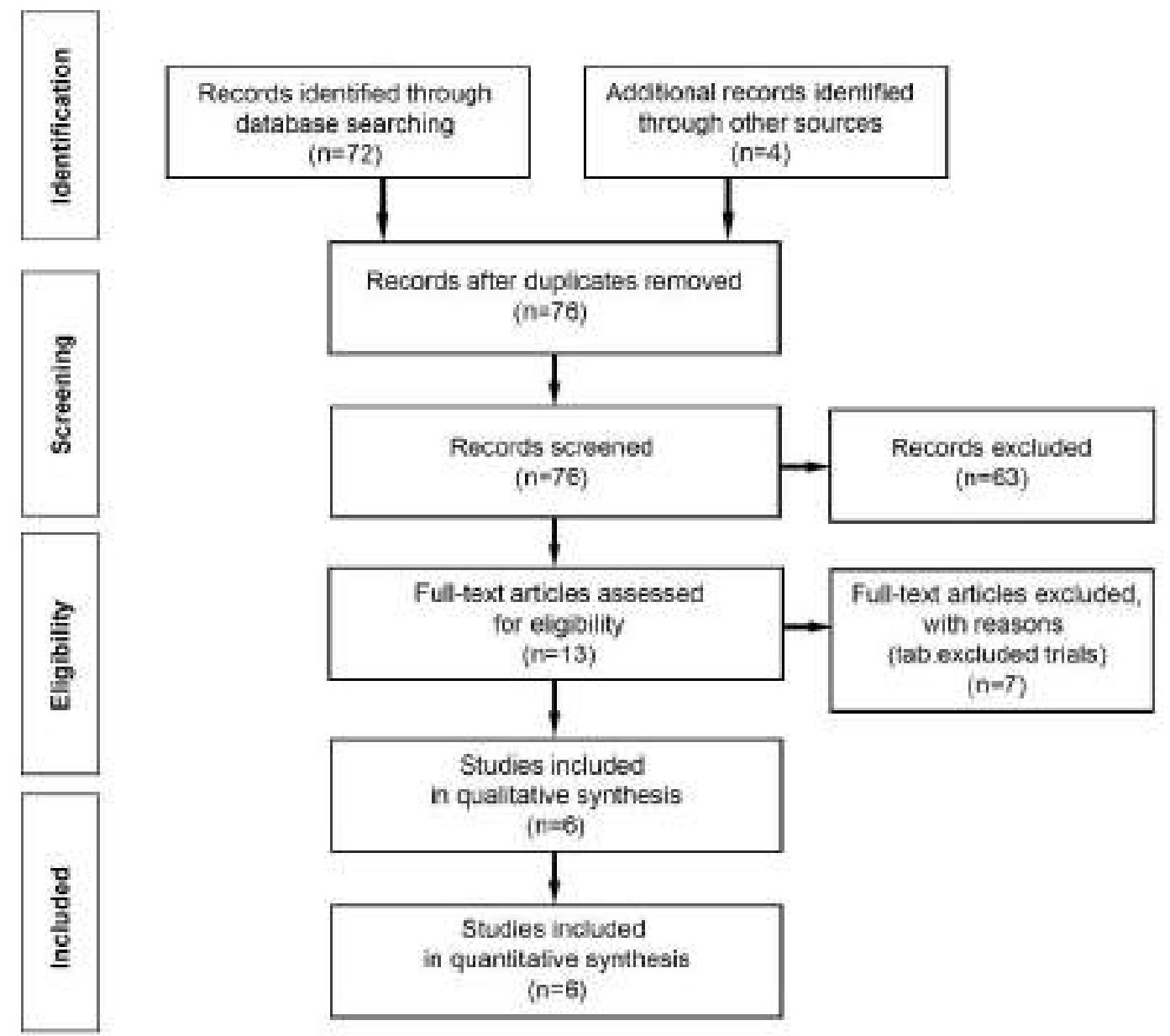

Figure 1. PRISMA flow diagram of the analyzed papers

costs was evaluated only from Wanner, that did not report any data but only the conclusion about NPWT "cheaper than the traditional dressings", 28 other studies reported the indirect costs as the discharge from hospital, the mean number of treatment visits per week or the median number of dressing changes per day. Dwivedi reported that the hospital stay was significantly lower $(\mathrm{p}=0.001)$ in NPWT at week 2.24 Ashby reported a lower mean number of treatment visits per week in patients who underwent NPWT (3 vs 6) ${ }^{25}$ whereas Wild reported only that lower dressing changes resulted in patients who underwent NPWT ${ }^{27}$ (Tab. IV]. The quality of life was evaluated only from Wanner and it was better in patients underwent NPWT, but without reporting of any data.28 In the surgical wounds healing by secondary intention (SWHSI) all the studies described the type of procedure performed and the locations of the incision.

\section{Discussion}

The wound healing is a complex regenerative process with multifactorial determination. Despite the recent advance in medicine the patients with various pressure ulcers still represent a major concern due to lack of an effective treatment.
Moreover, in the light of the modern laparoscopic surgery and a strive to diminish hospital costs these patients are not "desirable" because of the significant burden on the nursing staff, prolonged hospital stay, expensive treatment and unsatisfactory results. The total cost in United Kingdom is between 1.4 and 2.1 billion annually, ${ }^{4}$ which is confirmed by a recent systematic review! $\frac{30}{}$ Unfortunately, despite the intensive research in this particular area, there are few RCTs in the literature yet. The evidence-based analysis of Medical Advisory Secretariat of Ontario Ministry of Health and LongTerm Care published in 2009 concluded that "the role of NPWT in chronic pressure ulcers remains unclear" 31 A Cochrane based systematic review of RCTs of Dumville et al. published in 2015, reported ,no rigorous RCT evidence available regarding the effects of NPWT compared with alternatives for the treatment of pressure ulcers. High uncertainty remains about the potential benefits or harms, or both, of using this treatment for pressure ulcer management" $\$ 32$ In this systematic review, six randomized controlled trials were included. ${ }^{24}$ In the two groups the characteristics of patients were similar, but the high heterogeneity regarding interventions, comparisons and outcomes rendered the data 
Table I

EXCLUDED STUDIES

\begin{tabular}{|c|c|c|c|c|c|c|c|}
\hline \multicolumn{2}{|c|}{$\begin{array}{l}\text { Author, year of publi- } \\
\text { cation }\end{array}$} & \multicolumn{6}{|c|}{ Reasons of exclusion } \\
\hline \multicolumn{2}{|l|}{ de Laat 2017} & \multicolumn{6}{|c|}{ A cross-sectional survey self-management of pressure ulcer prevention in adult paraplegics. } \\
\hline \multicolumn{2}{|l|}{ Skrinjar 2016} & \multicolumn{6}{|c|}{$\begin{array}{l}\text { In this randomized controlled trial the Authors analyzed, } 60 \text { consecutive patients with chronic leg wounds or surgical site infections } \\
\text { after revascularization of lower extremities and compared of Negative Pressure Wound Therapy additional polymeric membrane } \\
\text { interface dressing (PMD; PolyMem WIC) versus Negative Pressure Wound Therapy alone }\end{array}$} \\
\hline \multicolumn{2}{|c|}{ Sáez-Martín 2015} & \multicolumn{6}{|c|}{$\begin{array}{l}\text { In this randomized controlled trial the Authors analyzed ten patients with nonhealing ulcers and compared a novel biocompatible } \\
\text { polyurethane foam versus the conventional foam }\end{array}$} \\
\hline \multicolumn{2}{|l|}{ Wagstaff 2014} & \multicolumn{6}{|c|}{$\begin{array}{l}\text { In this randomized controlled trial the Authors analyzed twenty pressure ulcers and compared negative pressure and nanocrystalline } \\
\text { silver dressings versus negative pressure wound therapy alone }\end{array}$} \\
\hline \multicolumn{2}{|l|}{ Tuncel 2013} & \multicolumn{6}{|c|}{$\begin{array}{l}\text { In this randomized controlled trial the Authors analyzed } 50 \text { consecutive patients with wound and compared conventional antiseptic } \\
\text { (polyhexanide solution) dressings, versus saline-soaked antibacterial gauze-based negative pressure wound therapy }\end{array}$} \\
\hline \multicolumn{2}{|l|}{ Dunn 2011} & \multicolumn{6}{|c|}{$\begin{array}{l}\text { This prospective multi-center non-comparative study reported the use of gauze-based Negative Pressure Wound Therapy in } 131 \\
\text { patients with in chronic and acute wounds }\end{array}$} \\
\hline \multicolumn{2}{|c|}{ Kordestani 2008} & \multicolumn{6}{|c|}{$\begin{array}{l}\text { In this randomized controlled trial the Authors analyzed eighty-five patients with diabetic foot ulcers, pressure ulcers or leg ulcers } \\
\text { and compared bioactive study dressing versus control dressing alone }\end{array}$} \\
\hline \multicolumn{8}{|c|}{$\begin{array}{c}\text { Table II } \\
\text { CHARACTERISTICS OF THE INCLUDED STUDIES }\end{array}$} \\
\hline & \multicolumn{2}{|c|}{ Type of study } & $\begin{array}{l}\text { Nation were } \\
\text { perfomed the trial }\end{array}$ & $\begin{array}{l}\text { Etiology of immobi- } \\
\text { lization }\end{array}$ & $\begin{array}{l}\text { Location of ulcers } \\
\text { and stage }\end{array}$ & $\begin{array}{l}\text { Patients } \\
\text { underwent } \\
\text { NPWT }\end{array}$ & $\begin{array}{l}\text { Patients } \\
\text { underwent } \\
\text { conventional } \\
\text { treatment }\end{array}$ \\
\hline $\begin{array}{l}\text { Dwivedi } \\
2016\end{array}$ & \multicolumn{2}{|l|}{ RCT } & India & Traumatic paraplegia & $\begin{array}{l}\text { Sacral / III and IV } \\
\text { stage }\end{array}$ & 21 & 23 \\
\hline Ashby 2012 & \multicolumn{2}{|l|}{$\mathrm{RCT}$} & UK & NR & $\begin{array}{l}\text { Heel, Trochanter, } \\
\text { Sacrum, Gluteal, } \\
\text { Ischial / III and IV } \\
\text { stage }\end{array}$ & 6 & 6 \\
\hline \multicolumn{3}{|l|}{2011} & The Netherlands & Traumatic paraplegia & NR / IV stage & 6 & 6 \\
\hline Wild 2008 & \multicolumn{2}{|l|}{$\mathrm{RCT}$} & Austria & NR & $\begin{array}{l}\text { Sacral / III and IV } \\
\text { stage }\end{array}$ & 5 & 5 \\
\hline Wanner 2003 & \multicolumn{2}{|l|}{$\mathrm{RCT}$} & Switzerland & Traumatic paraplegia & $\begin{array}{l}\text { Sacral / III and IV } \\
\text { stage }\end{array}$ & 11 & 11 \\
\hline Ford 2002 & \multicolumn{2}{|l|}{$\mathrm{RCT}$} & USA & NR & $\begin{array}{l}\text { Ischial, Sacral, } \\
\text { Lateral malleolar, } \\
\text { Trochanter and } \\
\text { Calcaneal / IV stage }\end{array}$ & 20 & 21 \\
\hline
\end{tabular}

not suitable to perform meta-analysis. All trials have agreed that the pressure ulcers healed better in patients underwent NPWT, but the data reported are very poor. Ashby showed that only one pressure ulcer (17\%) healed in NPWT group, 25 whereas de Laat reported only a "statistically significantly faster wound healing".26 Different results were found in the trials that described the reduction in ulcer volume with different type of measure - length and width of ulcer, mean (SD) time to reach $50 \%$ of the initial volume, mean percent reduction in ulcer volume). In this outcome the results are different: Dwivedi reported statistically significant better results in patients underwent NPWT ${ }^{24}$ In contrast, Wanner $^{28}$ and Ford ${ }^{29}$ did not find a significant difference between the two groups. A small retrospective case series of 20 patients with various wounds ( 2 pressure ulcers) reported mean reduction of wound area with $29 \%$ after treatment with V.A.C. $\AA(\mathrm{KCI}){ }^{33}$ The authors reported reduction of the pressure ulcers size with 52 and $13 \mathrm{~mm}$ after 26 and 32 days with NPWT, respectively. In a RCT (79\% pressure ulcers)
Joseph et al. reported volume reduction in $78 \%$ in NPWT vs. $30 \%$ in the conventional group and $64 \%$ granulation tissue proven histologically after 6 -weeks treatment. ${ }^{34}$ Despite the low evidence level several case reports showed reduction of wound volume and complete healing in two months. 35$] 36$ The same problem was encountered in the analysis of very heterogeneous characteristics for the local evaluation of ulcer improvement. One study showed only few significantly better results in patients underwent NPWT (lower exudates in NPWT group at weeks 4 and 9, higher conversion of slough into red granulation tissue and an increase of the surface granulation) ${ }^{24}$ Differently, the other evaluations reported no advantage in macroscopic (newly-formed granulation tissue and wound contracture, absolute and relative proportion of fibrin tissue at the wound base and of necrosis) 27, 28 and biopsy evaluation (mean number of PMNs and lymphocytes per high-power field and mean number of capillaries per high-power field) ${ }^{29}$ In the most recent work from China the authors compare conventional treatment with NPWT 
Table III

RISK OF BIAS. (YES E.G. LOW RISK OF BIAS; No E.G. HIGH RISK OF BIAS)

\begin{tabular}{llllll}
\hline & Selection bias & Performance bias & Attrition bias & Detection bias & Reporting bias \\
\hline Dwivedi 2016 & Yes & Yes & Unknown & Unknown & Yes \\
Ashby 2012 & Yes & Yes & Yes & Yes & Yes \\
De Laat 2011 & Yes & Yes & Unknown & No & Yes \\
Wild 2008 & Yes & Yes & Unknown & Unknown & Ynknown \\
Wanner 2003 & Unknown & Unknown & Unknown & Unknown & Yes \\
Ford 2002 & Yes & Yes & Unknown & Yes & \\
\hline
\end{tabular}

Table IV

COMPARISON OF THE THERAPY OUTCOMES AFTER THE INTRODUCTION OF NPWT

\begin{tabular}{|c|c|c|}
\hline & Lesion reduction & Outcomes \\
\hline $\begin{array}{l}\text { Ashby } \\
2012\end{array}$ & $\begin{array}{l}\text { Only one pressure ulcer healed (NPWT group) during follow-up (time } \\
\text { to healing } 79 \text { days). }\end{array}$ & $\begin{array}{l}\text { mean number of treatment visits per week: } 3.1(\mathrm{NPWT}) \text { and } 5.7(\mathrm{SC}) \text {; } \\
6 / 6 \mathrm{NPWT} \text { and } 1 / 6 \mathrm{SC} \text { participants withdrew from their allocated trial } \\
\text { treatment. }\end{array}$ \\
\hline $\begin{array}{l}\text { De Laat } \\
2011\end{array}$ & $\begin{array}{l}\text { statistically significantly faster wound healing in the topical negative } \\
\text { pressure group }\end{array}$ & \\
\hline $\begin{array}{l}\text { Dwivedi } \\
2016\end{array}$ & $\begin{array}{l}\text { Significantly }(\mathrm{p}<0.01) \text { decreased in NPWT group as compared with } \\
\text { standard care group at week } 9 \text {. At weeks } 1,2 \text { and } 3 \text {, depth was } \\
\text { significantly }(\mathrm{p}<0.05) \text { higher in NPWT group, whereas at week } 9 \text { a } \\
\text { significant reduction }(\mathrm{p}=0.01) \text { was observed }\end{array}$ & $\begin{array}{l}\text { Secretion: Significantly }(\mathrm{p}=0.001) \text { lower in NPWT group at weeks } 4 \\
\text { and } 9 \text {; Conversion of slough into red granulation tissue: Significantly } \\
\text { higher in NPWT group }(\mathrm{p}=0.001\end{array}$ \\
\hline $\begin{array}{l}\text { Wanner } \\
2003\end{array}$ & $\begin{array}{l}27(10) \text { days in the vacuum-assisted group and } 28(7) \text { in the traditional } \\
\text { group }\end{array}$ & $\begin{array}{l}\text { Discharge from hospital }(\mathrm{p}=0.001) \text { lower in NPWT at week } 2 \\
\text { Newly-formed granulation tissue and wound contracture (measured the } \\
\text { volume instead of the area of the usually undermined wounds) equally } \\
\text { effective } \\
\text { NPWT cheaper than traditional dressings, QoL improved more }\end{array}$ \\
\hline $\begin{array}{l}\text { Ford } \\
2002\end{array}$ & $42.1 \%$ with HP and $51.8 \%$ with VAC $(p=0.46)$ & $\begin{array}{l}\text { Mean number of PMNs and lymphocytes per high-power field: De- } \\
\text { creased in the VAC group and increased in the HP group } \\
\text { Mean number of capillaries per high-power field: The mean number } \\
\text { of capillaries per high-power field was greater in the VAC group } \\
\text { Improved biopsy-proven osteomyelitis underlying the ulcers: Improved } \\
\text { with VAC }\end{array}$ \\
\hline Wild & $\begin{array}{l}\text { Increase in fibrin tissue at the wound base of } 21.8 \% \text {, whereas in the } \\
\text { V.A.C group, a } 27 \% \text { reduction was observed }(P 0.035) \\
\text { Necrosis insignificantly reduced in the V.A.C. group }\end{array}$ & $\begin{array}{l}\text { Increase in surface granulation tissue of } 54 \% \text { was observed in the } \\
\text { V.A.C. group and a reduction in the Redon group }(P 0.001) \text {. }\end{array}$ \\
\hline
\end{tabular}

and NPWT plus microplasma using the following outcome measures - the maturity of granulations, growth degree of epithelium, blood perfusion, density of new vessels, wound area and total healing rate ${ }^{37}$ The combination of NPWT with microplasma yielded the best results followed by NPWT alone and conventional treatment. The quality of life (QoL) was evaluated in only one trial ${ }^{\sqrt[38]{3}}$ The authors reported a better quality in NPWT group, but without any data. Similarly, in various acute or chronic wounds, others reported better QoL 30 39 In fact, a true cost analysis was not performed. Wanner,28 wrote only that NPWT was "cheaper than the traditional dressings". In the other studies, reporting indirect costs (discharge from hospital, the mean number of treatment visits per week or the median number of dressing changes per day), the authors showed better results in NPWT group 24 25 In 2004 the German and Austrian Societies for Wound Healing and Wound Management stated that NPWT treatment is cost effective. ${ }^{38}$ In a RCT with 65 cases Braakenburg et al. reported similar overall costs ${ }^{40}$ In 2008, Apelqvist et al. reported significantly lower costs in NPWT group vs. standard moist wound therapy of diabetic foot wounds (with average $12852 \$$ )! ${ }^{41}$ A systematic review of National Health Service of UK supported the usage of NPWT in chronic wound management due to better QoL and improved cost effectiveness. ${ }^{39}$ The work encourages development of national guideline for NPWT in wound management.

\section{CONCLUSION}

NPWT is deemed appropriate and effective method and widely used by clinicians to promote the healing of wounds and ulcers of various etiology. High quality clinical studies are nevertheless few and do not allow to draw definitive conclusions. The analysis of the selected trials showed an overall favorable trend for NPWT compared to conventional therapy, in particular in a wounds with low secretion and presence of granulation tissue. This would seem to indicate that the NPWT should not be used too early in pressure ulcers. The heterogeneity found in individual trials regarding the inclusion criteria, therapeutic procedures, the criteria and methods of outcome evaluation, however, did not allow for a data evaluation with statistically valid conclusions. The outcome heterogeneity between studies suggests that NPWT cannot be indiscriminately considered the standard treatment for pressure ulcers. An adequate and detailed information should be provided, in order to acquire a valid patient's consent to NPWT. In fact, considering the lack of an effective treatment of pressure ulcers, the patient should be given an appropriate range of choices, in order to express his consent to undergo the best therapeutic option for the specific case. It is reasonable to assume that a subset of patients with pressure 
ulcers can be effectively treated with NPWT, with optimal results and good cost-benefit ratio, also with respect to the quality of life 41,42 Further clinical studies are needed on homogeneous groups of patients with homogeneous inclusion criteria, therapeutic procedures and outcome measures. In our opinion, it is mandatory to include patients with uniform characteristics in the new Randomised Controlled Trials' design: age, nutritional status, comorbidities, stage and size of pressure ulcers. Furthermore, we suggest to report the following principal outcomes: treatments failure rate, complete healing time, quality of life during treatment and wound care cost.

\section{ACKNOWLEDGEMENT}

\section{Gelfrido Galizi MD, Matteo Piobbichi PhD}

\section{REFERENCES}

[1] J. Cuddigan, D. R. Berlowitz, and E. A. Ayello, "Pressure ulcers in america: prevalence, incidence, and implications for the future," Advances in skin \& wound care, vol. 14, no. 4, p. 208, 2001.

[2] R. J. Hay, N. E. Johns, H. C. Williams, I. W. Bolliger, R. P. Dellavalle, D. J. Margolis, R. Marks, L. Naldi, M. A. Weinstock, S. K. Wulf et al., "The global burden of skin disease in 2010: an analysis of the prevalence and impact of skin conditions," Journal of Investigative Dermatology, vol. 134, no. 6, pp. 1527-1534, 2014.

[3] E. Hahnel, A. Lichterfeld, U. Blume-Peytavi, and J. Kottner, "The epidemiology of skin conditions in the aged: A systematic review," Journal of tissue viability, vol. 26, no. 1, pp. 20-28, 2017.

[4] S. Zaratkiewicz, J. D. Whitney, J. R. Lowe, S. Taylor, F. O'donnell, and P. Minton-Foltz, "Development and implementation of a hospitalacquired pressure ulcer incidence tracking system and algorithm," Journal for Healthcare Quality, vol. 32, no. 6, pp. 44-51, 2010.

[5] J. Black, M. M. Baharestani, J. Cuddigan, B. Dorner, L. Edsberg, D. Langemo, M. E. Posthauer, C. Ratliff, G. Taler et al., "National pressure ulcer advisory panel's updated pressure ulcer staging system," Advances in skin \& wound care, vol. 20, no. 5, pp. 269-274, 2007.

[6] M. J. Morykwas, L. C. Argenta, E. I. Shelton-Brown, and W. McGuirt, "Vacuum-assisted closure: a new method for wound control and treatment: animal studies and basic foundation." Annals of plastic surgery, vol. 38, no. 6, pp. 553-562, 1997.

[7] A. K. Greene, M. Puder, R. Roy, D. Arsenault, S. Kwei, M. A. Moses, and D. P. Orgill, "Microdeformational wound therapy: effects on angiogenesis and matrix metalloproteinases in chronic wounds of 3 debilitated patients," Annals of plastic surgery, vol. 56, no. 4, pp. 418-422, 2006.

[8] K. Norbury and K. Kieswetter, "Vacuum-assisted closure therapy attenuates the inflammatory response in a porcine acute wound healing model." Wounds: a compendium of clinical research and practice, vol. 19 , no. 4, pp. 97-106, 2007.

[9] D. A. Simhaee, A. Marsano, G. M. Fomovsky, G. Niedt, J. K. Wu et al., "Efficacy and mechanisms of vacuum-assisted closure (vac) therapy in promoting wound healing: a rodent model," Journal of Plastic, Reconstructive \& Aesthetic Surgery, vol. 62, no. 10, pp. 1331-1338, 2009.

[10] K. Nishimura, P. Blume, S. Ohgi, and B. E. Sumpio, "Effect of different frequencies of tensile strain on human dermal fibroblast proliferation and survival," Wound repair and regeneration, vol. 15, no. 5, pp. 646-656, 2007.

[11] D. Moher, A. Liberati, J. Tetzlaff, D. G. Altman, P. Group et al., "Preferred reporting items for systematic reviews and meta-analyses: the prisma statement," PLoS medicine, vol. 6, no. 7, p. e1000097, 2009.

[12] D. Sackett, W. Richardson, W. Rosenberg, and R. Haynes, "Evidencebased medicine: How to practice and teach ebm. 1997," Edinburgh: Churchill Livingstone, vol. 1.

[13] J. P. Higgins and S. Green, "Cochrane handbook for systematic reviews of interventions," vol. 4, 2011.

[14] J. Savović, H. E. Jones, D. G. Altman, R. J. Harris, P. Jüni, J. Pildal, B. Als-Nielsen, E. M. Balk, C. Gluud, L. L. Gluud et al., "Influence of reported study design characteristics on intervention effect estimates from randomized, controlled trials," Annals of internal medicine, vol. 157, no. 6, pp. 429-438, 2012.
[15] I. Abraha, A. Cherubini, F. Cozzolino, R. De Florio, M. L. Luchetta, J. M. Rimland, I. Folletti, M. Marchesi, A. Germani, M. Orso et al., "Deviation from intention to treat analysis in randomised trials and treatment effect estimates: meta-epidemiological study," bmj, vol. 350, p. h2445, 2015.

[16] S. P. Hozo, B. Djulbegovic, and I. Hozo, "Estimating the mean and variance from the median, range, and the size of a sample," $B M C$ medical research methodology, vol. 5, no. 1, p. 13, 2005.

[17] L. C. Sáez-Martín, L. García-Martínez, C. Román-Curto, M. V. Sánchez-Hernández, and R. M. Suárez-Fernández, "Negative pressure and nanocrystalline silver dressings for nonhealing ulcer: A randomized pilot study," Wound Repair and Regeneration, vol. 23, no. 6, pp. 948-952, 2015.

[18] M. J. D. Wagstaff, S. Driver, P. Coghlan, and J. E. Greenwood, "A randomized, controlled trial of negative pressure wound therapy of pressure ulcers via a novel polyurethane foam," Wound Repair and Regeneration, vol. 22, no. 2, pp. 205-211, 2014.

[19] R. Dunn, T. Hurd, P. Chadwick, J. Cote, J. Cockwill, T. Mole, and J. Smith, "Factors associated with positive outcomes in 131 patients treated with gauze-based negative pressure wound therapy," International Journal of Surgery, vol. 9, no. 3, pp. 258-262, 2011.

[20] S. Kordestani, M. Shahrezaee, M. Tahmasebi, H. Hajimahmodi, D. Haji Ghasemali, and M. Abyaneh, "A randomised controlled trial on the effectiveness of an advanced wound dressing used in iran," $J$ Wound Care, vol. 17, no. 7, pp. 323-7, 2008.

[21] U. Tuncel, Ü. Erkorkmaz, and A. Turan, "Clinical evaluation of gauze-based negative pressure wound therapy in challenging wounds," International wound journal, vol. 10, no. 2, pp. 152-158, 2013.

[22] E. Skrinjar, N. Duschek, G. S. Bayer, O. Assadian, S. Koulas, K. Hirsch, J. Basic, and A. Assadian, "Randomized controlled trial comparing the combination of a polymeric membrane dressing plus negative pressure wound therapy against negative pressure wound therapy alone: The wicvac study," Wound Repair and Regeneration, vol. 24, no. 5, pp. 928-935, 2016.

[23] H. de Laat, A. de Munter, M. van der Burg, D. Ulrich, and O. Kloeters, "A cross-sectional study on self-management of pressure ulcer prevention in paraplegic patients," Journal of tissue viability, vol. 26, no. 1 , pp. 69-74, 2017.

[24] M. Dwivedi, R. Srivastava, A. Bhagat, R. Agarwal, K. Baghel, A. Jain, and S. Raj, "Pressure ulcer management in paraplegic patients with a novel negative pressure device: a randomised controlled trial," Journal of wound care, vol. 25, no. 4, pp. 199-207, 2016.

[25] R. L. Ashby, J. C. Dumville, M. O. Soares, E. McGinnis, N. Stubbs, D. J. Torgerson, and N. Cullum, "A pilot randomised controlled trial of negative pressure wound therapy to treat grade iii/iv pressure ulcers [isrctn69032034]," Trials, vol. 13, no. 1, p. 119, 2012.

[26] E. H. de Laat, M. H. van den Boogaard, P. H. Spauwen, D. H. van Kuppevelt, H. van Goor, and L. Schoonhoven, "Faster wound healing with topical negative pressure therapy in difficult-to-heal wounds: a prospective randomized controlled trial," Annals of plastic surgery, vol. 67, no. 6, pp. 626-631, 2011.

[27] T. Wild, S. Stremitzer, A. Budzanowski, T. Hoelzenbein, C. Ludwig, and G. Ohrenberger, "Definition of efficiency in vacuum therapya randomised controlled trial comparing redon drains with vac $\mathbb{R}$ therapy ${ }^{\mathrm{TM}}$," International wound journal, vol. 5, no. 5, pp. 641-647, 2008

[28] M. B. Wanner, F. Schwarzl, B. Strub, G. A. Zaech, and G. Pierer, "Vacuum-assisted wound closure for cheaper and more comfortable healing of pressure sores: a prospective study," Scandinavian journal of plastic and reconstructive surgery and hand surgery, vol. 37, no. 1, pp. $28-33,2003$

[29] C. N. Ford, E. R. Reinhard, D. Yeh, D. Syrek, A. de las Morenas, S. B. Bergman, S. Williams, and C. A. Hamori, "Interim analysis of a prospective, randomized trial of vacuum-assisted closure versus the healthpoint system in the management of pressure ulcers," Annals of plastic surgery, vol. 49, no. 1, pp. 55-61, 2002.

[30] L. Demarré, A. Van Lancker, A. Van Hecke, S. Verhaeghe, M. Grypdonck, J. Lemey, L. Annemans, and D. Beeckman, "The cost of prevention and treatment of pressure ulcers: a systematic review," International journal of nursing studies, vol. 52, no. 11, pp. 17541774, 2015.

[31] H. Q. Ontario et al., "Management of chronic pressure ulcers: an evidence-based analysis," Ontario health technology assessment series, vol. 9, no. 3, p. 1, 2009.

[32] J. C. Dumville, J. Webster, D. Evans, and L. Land, "Negative pressure wound therapy for treating pressure ulcers," status and date: New, published in, no. 5, 2015. 
[33] D. de Alcântara Jones, W. Vasconcelos Neves Filho, J. de Souza Guimarães, D. de Araújo Castro, and A. Marcos Ferracini, "The use of negative pressure wound therapy in the treatment of infected wounds. case studies," vol. 51, 112016.

[34] E. Joseph, C. Hamori, B. SB, E. Roaf, N. F. Swann, and G. W. Anastasi, "A prospective randomized trial of vacuum-assisted closure versus standard therapy of chronic nonhealing wounds," vol. 12, pp. 60-67, 052000.

[35] R. Batra and V. Aseeja, "Vac therapy in large infected sacral pressure ulcer grade iv-can be an alternative to flap reconstruction?" Indian Journal of Surgery, vol. 76, no. 2, pp. 162-164, 2014.

[36] K. W. Broder, B. Nguyen, and R. M. Bodor, "Negative pressure wound therapy with instillation in a chronic non-healing right hip trochanteric pressure ulcer," Cureus, vol. 8, no. 11, 2016.

[37] Z. Li, Q. Wang, W. Mi, M. Han, F. Gao, G. Niu, and Y. Ma, "Effects of negative-pressure wound therapy combined with microplasma on treating wounds of ulcer and the expression of heat shock protein 90," Experimental and Therapeutic Medicine, vol. 13, no. 5, pp. 2211-2216, 2017.

[38] T. Wild, W. Wetzel-Roth, and G. Zöch, "Consensus of the german and austrian societies for wound healing and wound management on vacuum closure and the vac treatment unit." Zentralblatt fur Chirurgie, vol. 129, pp. S7-11, 2004.

[39] D. Othman, "Negative pressure wound therapy literature review of efficacy, cost effectiveness, and impact on patients' quality of life in chronic wound management and its implementation in the united kingdom," Plastic surgery international, vol. 2012, 2012.

[40] A. Braakenburg, M. C. Obdeijn, R. Feitz, I. A. van Rooij, A. J. van Griethuysen, and J. H. Klinkenbijl, "The clinical efficacy and cost effectiveness of the vacuum-assisted closure technique in the management of acute and chronic wounds: a randomized controlled trial," Plastic and reconstructive surgery, vol. 118, no. 2, pp. 390397, 2006.

[41] J. Apelqvist, D. G. Armstrong, L. A. Lavery, and A. J. Boulton, "Resource utilization and economic costs of care based on a randomized trial of vacuum-assisted closure therapy in the treatment of diabetic foot wounds," The American Journal of Surgery, vol. 195, no. 6, pp. 782-788, 2008.

[42] J. Niezgoda, "A comparison of vacuum assisted closure therapy to moist wound care in the treatment of pressure ulcers: Preliminary results of a multicenter trial. abstract x001," Abstract X001, 2004. 